\title{
Proses Repairing Ponton di PT. Dok dan Perkapalan Surabaya
}

\author{
Soeryanto ${ }^{1}$, Abdul Aziz Mashuri ${ }^{2}$, Bina Samudra ${ }^{3}$ \\ 1,2 Jurusan Teknik Mesin, Universitas Negeri Surabaya \\ ${ }^{3}$ PT. Dok dan Perkapalan Surabaya \\ soeryanto@unesa.ac.id
}

\begin{abstract}
Abstrak-Indonesia memiliki letak geografis yang strategis sehingga dilalui berbagai jalur pelayaran dunia karena menghubungkan jalur pelayaran antar dua benua besar sehingga armada kapal sendiri merupakan salah satu sarana yang dapat digunakan untuk kebutuhan akses dan konektivitas antar pulau di Indonesia. Namun, kapasitas galangan di Indonesia masih kurang memadai dibandingkan jumlah kapal yang membutuhkan reparasi sehingga sering terjadi kapal sandar beberapa hari untuk mengantri atau menunggu giliran untuk reparasi. Proses reparasi kapal (pengedokan) yang paling sering digunakan di PT.DPS adalah menggunakan fasilitas floating dock. Seperti layaknya kapal perlu adanya maintenance dan reparasi, setiap beberapa tahun sekali floating dock selalu ada reparasi berkala terutama pada bagian ponton yang paling krusial bersentuhan dengan air laut sehingga mudah terkorosi, untuk menjaga keamanan dan kualitas yang dihasilkan. Proses Repairing ponton merupakan suatu proses perbaikan ponton floating dock agar kekuatan angkat floating dock tetap terjaga, proses tersebut memerlukan tahapan-tahapan yang sedetail mungkin mulai dari Handling, Ident Material, Marking, Cutting, Bending, Joint Plate, Fit-up scantling, Joint Pannel, Welding, Firing, NDT, Blasting \& Coating, Final Inspection dan pengujian yang berkala untuk meminimalisir kesalahan-kesalahan yang akan timbul dalam proses pengerjaanya.
\end{abstract}

Kata Kunci- repairing, ponton, kapal.

Abstract-Indonesia has a strategic geographical location so that various world shipping routes are passed because it connects shipping lines between two major continents so that the fleet itself is one of the facilities that can be used for the needs of access and connectivity between islands in Indonesia. However, shipyard capacity in Indonesia is still inadequate compared to the number of ships that require repairs so that there are frequent berths for several days to queue or wait their turn for repairs. The ship repair process (docking) that is most often used in PT.DPS is to use the floating dock facility. Like a ship, it is necessary to have maintenance and repairs, every few years a floating dock always has periodic repairs, especially on the pontoon which is most crucial in contact with sea water so that it is easily corroded, to maintain the safety and quality produced. The repairing pontoon process is a repair process for the floating dock so that the floating dock's lift strength is maintained, the process requires as many detailed steps as possible from Handling, Identification Material, Marking, Cutting, Bending, Joint Plate, Fit-up Scantling, Joint Pannel, Welding, Firing, NDT, Blasting \& Coating, Final Inspection and periodic testing to minimize errors that will arise in the process of processing.

Keywords — repairing, pontoon, ship.

\section{Pendahuluan}

Indonesia merupakan Negara Kepulauan terbesar di dunia. Alat transportasi laut sangat diperlukan di Indonesia. Sementara armada kapal sendiri merupakan salah satu sarana yang dapat digunakan untuk kebutuhan akses dan konektivitas antar pulau di Indonesia. Namun kapasitas galangan di Indonesia masih kurang memadai dibandingkan jumlah kapal yang membutuhkan reparasi sehingga sering terjadi kapal sandar beberapa hari untuk mengantri atau menunggu giliran untuk reparasi.

Proses reparasi kapal (pengedokan) yang paling sering digunakan di PT. DPS adalah menggunakan fasilitas floating dock. Floating dock tersebut akan mengangkat kapal ke permukaan dengan bantuan pompa dengan mengeluarkan semua air yang berada di dalam lambung floating dock (Ponton) untuk berganti dengan oksigen. Sehinga memudahkan proses reparasi karena dilakukan di atas permukaan air. Seperti layaknya kapal perlu adanya maintenance dan reparasi, setiap beberapa tahun sekali floating dock selalu ada reparasi berkala terutama pada bagian ponton yang paling krusial bersentuhan dengan air laut sehingga mudah terkorosi, untuk menjaga keamanan dan kualitas yang dihasilkan.

\section{TINJAUAN PUSTAKA}

\section{A. Definisi Pengedokan Kapal}

Pengedokan Kapal adalah proses yang digunakan untuk memindahkan kapal dari air atau laut keatas dock dengan fasilitas bantuan pengedokan. Setiap kapal yang berbendera Indonesia yang beroperasi wajib didaftarkan pada Badan Klasifikasi Indonesia (BKI) yang bertugas sebagai wakil dari pemerintah Indonesia yang bertanggung jawab melalukukan survey kelayakan kapal. Hasil survey tersebut, ditentukanlah beberapa item pekerjaan docking repair kapal sebagai upaya menjaga kondisi kapal laut agar tetap handal dan layak [3].

Menurut Badan Klarifikasi Indonesia (BKI) periode pelaksanaan survey dapat dilakukan, antara lain:

1. Annual survey (survey tahunan) Survey yang dilaksanakan setiap satu tahun sekali.

2. Intermediate survey ( survey 2,5 tahunan).

3. Renewal survey / special survey ( survey 5 tahunan).

4. Other complete periodical survey. 
[3]:

Jenis-jenis Galangan kapal (shipyard) diantaranya

1. Building dock shipyard

Building dock shipyard adalah tempat yang digunakan hanya dalam ruang lingkup pembangunan kapal baru (New Building).

2. Repair dock shipyard

Repair dock shipyard adalah tempat yang digunakan hanya ruang lingkup perbaikan kapal (repair) dan pemeliharaan kapal (maintenance).

3. Building and repair shipyard

Tempat yang dapat digunakan dalam ruang lingkup baik pembangunan kapal baru dan repar atau maintenance

Menurut Bambang Saat kapal akan melakukan pengedokan, ada beberapa hal yang harus diperhatikan dan dipersiapkan sebelum kapal masuk dock [4], antara lain:

1. Catatan perbaikan. Dengan tujuan untuk menetahui dana yang kemungkinan dikeluarkan untuk melakukan pengedokan dan juga estimasi waktu yang diperlukan.

2. Persiapan keselamatan dan keamanan kapal selama dry docking.

3. Persyaratan kelas periodic.

4. Laporan-laporan dari engine dan perawatan.

5. Laporan-laporan dari fleet supervisor.

Pada saat kapal akan melakukan docking, maka dari pihak kapal harus memberikan dokumentsidokumentasi terkait untuk memberikan infrormasi mendetail mengenai keadaan kapal, dokumentasi yang dimaksud adalah Informasi kapal :

- Ukuran utama kapal.

- Gambar rencana garis.

- Gambar rencana umum.

- Gambar bukaan kulit.

- Sertifikat-sertifikat kapal.

- Gambar tangki-tangki.

Macam sistem pengedokan yang digunakan untuk repair sebuah kapal antara lain [3]:

1. Dok Kolam (Graving Dock)

Dok kolam yang sering juga disebut Dok Gali adalah suatu bangunan dok berbentuk kolam yang terletak ditepi laut atau sungai. Dok kolam mempunyai dinding yang kokoh seperti kolam renang karena pada saat kosong, Dok akan menerima tekanan tanah dari sekitarnya, sedangkan pada saat ada kapal yang akan dimasukkan kedalam atau dikeluarkan dari dalam Dok kolam tersebut, beban berat air akan diterima oleh dinding dan lantai Dok kolam tersebut.

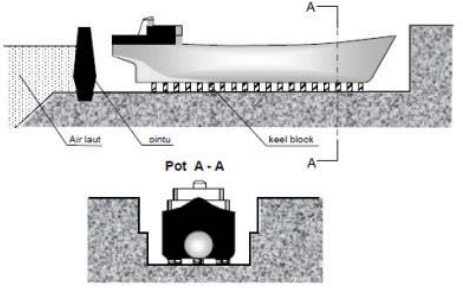

Gbr 1. Graving Dock

Untuk keluar masuknya kapal dari Dok kolam, maka Dok kolam mempunyai sebuah pintu. Pintu Dok kolam berbentuk seperti sebuahpontoon, terbuat dari suatu kontruksi baja, dimana pada pintu tersebutterdapat rongga - rongga yang dapat diisi air ataupun dikosongkan,sehingga pintu itu bisa terapung diatas air dan dipindahkan, apabilarongga-rongga tersebut telah dalam kondisi kosong. Selain itu juga dilengkapi dengan katup - katup yang dapat dibuka guna mengisi rongga - rongga tersebut dengan air supaya pintu itu tenggelam. Untuk mengeluarkan air baik dari rongga-rongga pada pintu maupun air yangberada pada kolam maka dok ini dilengkapi dengan pompa air.

Sebagai tempat untuk membangun atau memperbaiki kapal, maka sama dengan fasilitas tempat pembangunan kapal yang lain, Dok kolam dalam operasionalnya selalu dilayani dengan berbagai peralatan angkat (kran) yang mempunyai kapasitas angkat cukup besar, sesuai dengan kapasitas Dok kolam itu sendiri yang berjalan di sisi atas dinding Dok kolam tersebut. Urutan kerja mengoperasikan Dok Kolam (Graving Dock) untuk memasukkan kapal:

a. Keel Block (tempat dudukan kapal diatas dok) dipersiapkan. Diperiksa semua peralatan, tidak boleh ada yang nantinya mengapung apabila didalam air.

b. Katup-katup air pada Dok kolam dibuka sehingga air masuk kedalam Dok kolam, sampai permukaan air didalam dan diluarDok kolam sama tingginya.

c. Air di dalam rongga-rongga pintU dikeluarkan sampai pintu dapat terapung pintu terbuka) dan digeser atau dipindahkan.

d. Kapal masuk kedalam dok diatur agar tepat duduk diatas keel block (balok- balok ganjal) nya, sesuai metode yang digunakan.

e. Pintu ditarik, di gerakkan ke posisi menutup.

f. Katup-katup air pada pintu dibuka sehingga air masuk kedalam pintu dan pintu mulai tenggelam untuk menutup Dok kolam tersebut

g. Air didalam Dok kolam dipompa keluar 
dan bersamaan dengan surutnya air, kapal diatur supaya tepat duduk diatas keel block.

h. Karena kolam dalam kondisi kosong maka pintu akan mendapat tekanan dari air diluar kolam sehingga

\section{Dok Apung (Floating Dock)}

Dok apung atau floating dock adalah sebuah ba ngunan konstruksi berupa ponton - ponton yang dilengkapi dengan kran- kran pengangkat, pompapompa air dan perlengkapan tambat serta perlengkapan reparasi kapal lainnya. Yang mana konstruksi ini dapat ditenggelamkan atau diapungkan dalam arah vertikal.

\section{Cara kerja dok apung}

Sebelum dilakukan penenggelaman dok apung maka harus diketahui terlebih dahulu sarat kapal yang akan naik dok serta berapa meterkah bagianbagian yang menonjol dari kapal. Berdasarkan datadata yang diperoleh dari rencana dok (dock plan) maka dok apung ditenggelamkan dengan cara seluruh katup - katup pembagi dibuka dan air masuk kedalam rongga- rongga atau tangki pontom, sehingga dok secara perlahan turun. Harus dijaga agar kondisinya even keel. Jika sarat air diatas pontom telah mencapai sarat apung kapal maka dengan bantuan kapal tunda kapal akan ngedok didorong masuk ke dok apung dalam kondisi.

Mesin induk dan mesin bantu harus dimatikan. Selanjutnya diadakan penambatan kapal dengan talitali yang berfungsi untuk membatasi ruang gerak bagi kapal tersebut, sehingga lebih mudah untuk duduk pada ganjal- ganjal yang sudah disiapkan. Setelah kapal mulai masuk kedalam dok apung dan posisinya mencapai ketentuan yang diinginkan dan siap untuk duduk pada posisinya.

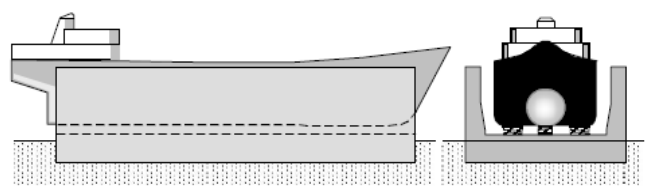

Gbr 2. Floating Dock

Jika mengalami trim maupun keolengan pada kapal, maka haruslah diusahakan menyeimbangkan- nya dengan memberi air balas, mengurangi, menambah atau memindah kannya. Sesudah posisi kapal stabil dan posisinya tepat sesuai dengan yang diinginkan, maka dok kembali diapungkan secara perlahan- lahan dan diadakan pengawasan, penjagaan, dan kontrol terhadap kedudukan dan posisi kapal. Untuk pengecekan posisi kapal apakah sudah tepat seusai ketentuan maka dilakukan penyelaman untukmemastikan kapal benar- benar duduk tepat pada ganjal- ganjal (keel block dan slide block.

3. Dok tarik ( Slip Way)

Dok tarik (Slip Way) adalah fasilitas pengedokan kapal dengan cara medudukan kapal diatas kereta yang disebut Trolley dan menarik kapal tersebut dari permukaan air dengan mesin Derek dan tali baja melalui suatu rel yang menjorok masuk kedalam perairan dengan kecondongan tertentu sampai ketepi perairan yang tidak terganggu oleh pasang surut dari air laut.

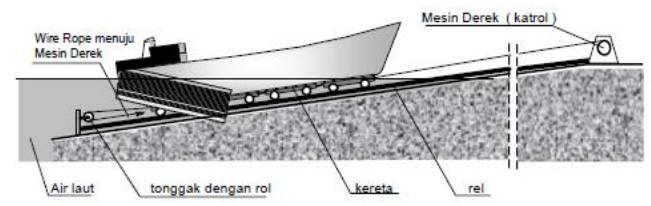

Gbr 3. Slip Way Dock

4. Dok Angkat (Syncrolife Dry dock)

Dok angkat atau Syncrolife Dry Dock adalah suatu fasilitas pengedokan kapal dengan menggunakan lift.

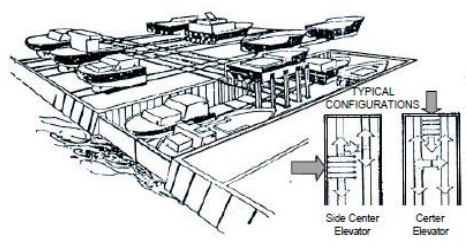

Gbr 4. Syncrolife Dry dock

Peralatan (plat form) dari dok angkat ini diturunkan dengan pertolongan pengantar lift. Dari beberapa mesin derek listrik yang terletak disebelah kanan dan kiri dari peralatan dok angkat ini. Setelah peralatan mencapai kedudukan tertentu kemudian kapal dimasukkan tepat diatas ganjal-ganjal (blok lurus atau pun balok samping) yang sudah disiapkan sebelumnya. Kemudian peralatan ini diangkat ke permukaan air

\section{B. Pengelasan}

Lambung kapal (Inggris: hull) adalah badan dari perahu atau kapal. Lambung kapal menyediakan daya apung yang mencegah kapal dari tenggelam. Rancang bangun lambung kapal merupakan hal yang penting dalam membuat kapal karena akan memengaruhi stabilitas kapal, kecepatan rencana kapal, konsumsi bahan 
bakar, draft/kedalaman yang diperlukan dalam kaitannya dengan kolam pelabuhan yang akan disinggahi serta kedalaman alur pelayaran yang dilalui oleh kapal tersebut [5].

Pengelasan merupakan salah satu bagian yang tak terpisahkan dari proses manufaktur. Proses pengelasan (welding) merupakan salah satu teknik penyambungan logam dengan atau tanpa tekanan dan dengan atau tanpa logam tambahan sehingga menghasilkan sambungan yang kotinu. Sedangkan definisi menurut Deutche Industrie and Normen (DIN), las adalah ikatan metalurgi pada sambungan logam atau logam paduan yang dilaksanakan dalam keadaan melting atau cair [Wiryosumarto, 1996].

Proses pengelasan memerlukan panas untuk meleburkan atau mencairkan logam dasar dan bahan pengisi agar terjadi aliran bahan atau peleburan. Energi pembangkit panas dapat dibedakan menurut sumbernya yaitu listrik, kimiawi, mekanis, dan bahan semikonduktor. Proses pengelasan yang paling umum, terutama untuk mengelas baja, yaitu memakai energi listrik sebagai sumber panas dan yang paling banyak digunakan adalah busur nyala (listrik). Busur nyala adalah pancaran arus listrik yang relatif besar antara elektroda dan logam dasar yang dialirkan melalui kolom gas ion hasil pemanasan. Berdasarkan masukan panas (heat input) utama yang diberikan kepada logam dasar atau induk, proses pengelasan dapat dibagi menjadi dua cara, yaitu [Wiryosumarto,1996].

\section{Pengujian NDT (Non Destrtructive Testing)}

Non destrtructive testing (NDT) adalah aktivitas tes atau inspeksi terhadap suatu benda untuk mengetahui adanya cacat, retak, atau discontinuity lain tanpa merusak benda yang kita tes atau inspeksi. Pada dasarnya, tes ini dilakukan untuk menjamin bahwa material yang kita gunakan masih aman dan belum melewati damage tolerance. Material pesawat diusahakan semaksimal mungkin tidak mengalami kegagalan (failure) selama masa penggunaannya.

NDT dilakukan paling tidak sebanyak dua kali. Pertama, selama dan diakhir proses fabrikasi, untuk menentukan suatu komponen dapat diterima setelah melalui tahap-tahap fabrikasi. NDT ini dijadikan sebagai bagian dari kendali mutu komponen. Kedua, NDT dilakukan setelah

\section{METODE}

Metode dalam kegiatan ini diantaranya yaitu:

A. Observasi, Secara langsung mengamati bagaimana proses repairing pontoon di PT. Dok Dan Perkapalan Surabaya (Persero).

B. Wawancara,
Mewawancarai karyawan baik dari pihak PT. Dok Dan Perkapalan Surabaya (Persero) dan pekerja subkontraktor tentang segala sesuatu yang berkaitan dengan proyek tersebut.

C. Literatur

Membaca buku-buku, laporan, atau sumber kepustakaan lain yang berkaitan dengan pengecatan pada kapal.

\section{HASIL DAN PEMBAHASAN}

\section{A. Perancangan dan Persiapan Gambar Kerja}

Tahapan pertama adalah sebuah patokan untuk mempermudah pekerjan dalam pencapian sebuah tujuan seperti dalam mempersiapkan gambar kerja seperti rencana garis (Lines plan, Body plan), Rencana umum (General arrangement), Bukaan kulit (Shell expansion), Penampang melintang dan konstruksi profil (Midship section). Sehingga selanjutnya menjadi kesatuan sebuah desain gambar kerja.

\section{B. Pemesanan Material / Handling}

Pemesanan material merupakan pekerjaan untuk mempersiapkan material yang dibutuhkan dari produsen untuk kebutuhan proyek sehingga projek dapat langsung dikerjakan. dalam tahap ini proses penyeleksian jenis bahan sangat dibutuhkan agar konstuksi dari bangunan baru dapat bertahan sesuai keinginan.

P. 150001/H.0301

\section{RENCANA KEBUTUHAN MATERIAL (Material Requirement Plan)}

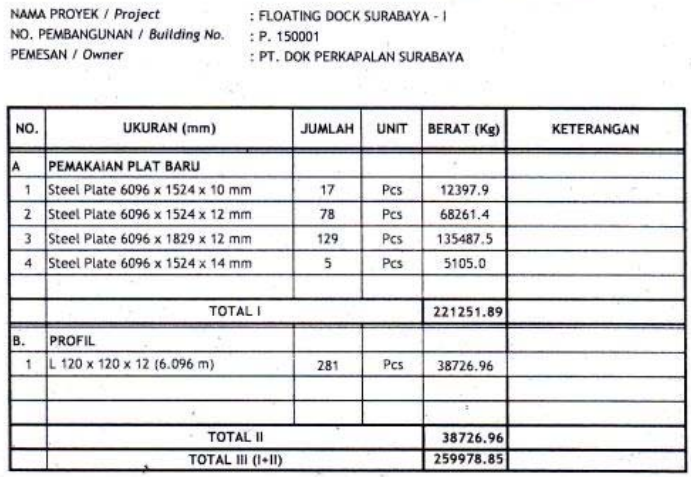

Gbr 5. Rencana kebutuhan material

\section{Persiapan Tenaga Kerja}

Dalam proses persiapan dilakukan perencanaan kebutuhan akan sumber daya manusia dengan menentukan berbagai pekerjaan yang mungkin timbul. Yang dapat dilakukan adalah dengan melakukan perkiraan / forecast akan pekerjaan yang lowong, jumlahnya, waktu, dan lain sebagainya. Ada dua faktor 
yang perlu diperhatikan dalam melakukan persiapan, yaitu faktor internal seperti jumlah kebutuhan karyawan baru, struktur organisasi, departemen yang ada, dan lainlain. Faktor eksternal seperti hukum ketenagakerjaan, kondisi pasa tenaga kerja, dan lain sebagainya.

D. Identifikasi Material

Proses pengidentifikasian material adalah proses pemeriksaan dan pendataan beberapa bahan yang sudah datang dari pengindenan dari produsen penyedia material bahan yang dibutuhkan atau material bahan yang sudah ada di dalam gudang bekas sisa material dari pembuatan bangunan baru yang sudah disepakati oleh owner pemesan. Dalam pengidentifikasian materiah tidak hanya satu devisi yang bertugas dalam pekerjaan tersebut, tetapi beberapa devisi yang terkait dalam pembangunan juga mempunyai tanggung jawab dalam pekerjaan tersebut

E. Marking

Marking adalah proses penandaan diatas permukaan material bahan yang mengacu pada gambar kerja agar memudahkan pada saat proses Cutting sehingga meminimalisir kesalahan pemotongan/cutting.

F. Cutting

Proses ini merupakan pemotongan material-material yang telah dimarking. Apabila marking tersebut disetujui oleh QA (Quality Assurance) maka pemotongan dapat dilakukan. Dalam proses pemotongan banyak faktor yang mempengaruhi hasil pemotongan, misalnya: pertama yaitu operator, keahlian operator sangat berperan penting dalam menentukan kualitas hasil potongan. Hal ini sangat terlihat sekali pada proses pemotongan dengan manual (brander). Kedua adalah mesin pemotong yang digunakan yaitu mengenai akurasi pemotongan pada mesin tersebut. Apabila hasil proses pemotongan kurang halus maka dilakukan penghalusan dengan gerinda. Kebanyakan hasil dari setiap proses pemotongan digerinda agar dalam proses berikutnya lebih mudah dan cepat. Selain mesin manual PT.DPS juga memiliki mesin potong CNC.

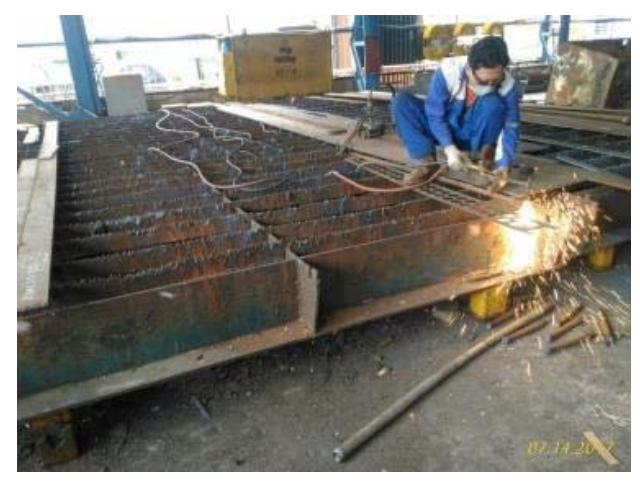

Gbr 6. Proses cutting secara manual

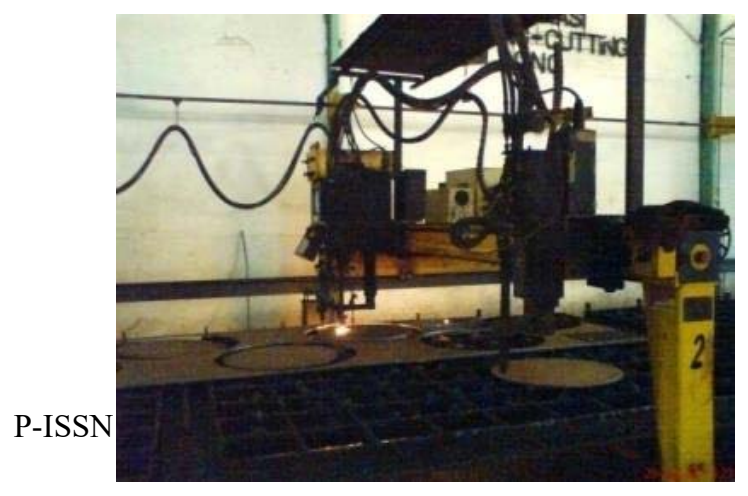

Soeryanto: Proses Repairing Ponton di PT. Dok dan .....
Gbr 7. Proses cutting secara otomatis berbasis CNC

\section{G. Bending}

Banyak bagian kapal yang berupa lengkungan, maka dari itu proses forming sangat diperlukan dalam pembuatan kapal. Berdasarkan proses pengerjaan, proses forming dibagi menjadi 2 jenis yaitu Mekanical Forming dan Thermal Forming.

H. Joint Plate

Joint Plate merupakan tahapan dimana setelah pelat-pelat yang sudah di cutting ataupun dibending di gabungkan dan disatukan dengan welding agar didapat hasil yang sesuai kebutuhan terhadap konstruksi baru. Alat- alat seperti kapur dan penitik sangat dibutuhkan sebagai alat uuntuk menandai posisi mana yang susuai utuk pelat tersebut. Agar didapat haasil yang maksimal welder harus menguasai betul segala teknik pengelasan segala jenis material logam. Setelah joint pelat dikerjakan didapatlah pannel (gabungan antara pelat-pelat yang sudah disatukan).

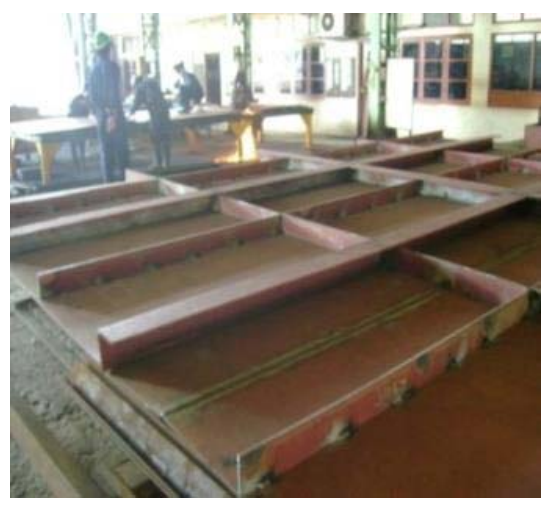

Gbr 7. Perakitan stiffeners pada floor

I. Fit - up scantling part

Pelat yang sudah di joint akan di setting dan dicenter kembali yang bertujuaN agar tidak ada lagi kesalahan yang yang dapat mengganggu kegiatan setelahnya.. Sebelum dilakukan proses sub assembly, hasil dari pekerjaan fabrikasi diperlukan untuk pengecekan baik bentuk maupun ukuran serta tandanya yang berguna untuk mengurangi kesalahan dalam pekerjaan sub assembly.

J. Joint pannel

Joint pannel merupakan proses penggabungan 
komponen komponen dari bengkel fabrikasi dari pelatpelat yang sudah disatukan menjadi sebuah panel. Komponen- komponen tersebut masih berupa plat dengan potongan lurus (parallel) maupun tidak lurus (nonparallel). Sebagai contoh proses pada Sub assembly ini adalah penggabungan antara lain: Merakit sekat, Merakit pangkon penumpu kayu dan Memasang deck

K. Welding dan deformation

Welding merupakan proses terakhir dari proses perakitan antara pelat-pelat ataupun panel-pannel dimana antara sambungan antara pelat-pelat di las sehingga bisa tersambung. Hal ini bertujuan agar ruang-ruang pada ponton tidak terjadi sirkulasi antara udara luar dengan udara dalam / vakum. Mesin las yang digunakan pada tahap ini adalah mesin las SMAW. Welder yang profesional sangat dibutuhkan dalam menghasilkan hasil pengelasan yang sempurna dan kendala pada saat pengelasan seperti terdeformasinya struktur dari pelat sehingga terjadi pembengkokan di área-area tertentu akibat akibat pengelasan dan tidak sesuainya antara panel akibat kesalahan dalam proses pemotonngan atau pengelasan seringkali dihadapi oleh para welder.

L. Firing

Firing adalah proses reforming setiap pelat yang terdeformasi akibat pengelasan agar bisa kembali ke bentuk semula. Sebagai contoh : apabila di bagian Shell plate yang sudah dilas dengan sekat air tadi diarea tersebut terjadi Deformasi/pembengkokan di tengahtengah bagian pengelasan tersebut yang mepunyai luasan $900 \mathrm{~m}^{2}$, diarea tersebutlah akan dipanaskan dengan las bender sampai mencapai temperatur tinggi tapi tidak sampai memeleh selanjutnya las akan dihentikan dan langsung dilakukan pendinginan langsung menggunakan air sehingga kembalilah area yang terdeformasi tersebut ke bentuk semula.

M. NDT (Non Destruktif Test)

Non destrtructive test (NDT) adalah aktivitas tes atau inspeksi terhadap suatu benda untuk mengetahui adanya cacat, retak, atau discontinuity lain tanpa merusak benda yang kita tes atau inspeksi. Pada dasarnya, tes ini dilakukan untuk menjamin bahwa material yang kita gunakan masih aman dan belum melewati damage tolerance.

\section{N. Blasting and Tank Coating}

Blasting adalah proses dimana keseluruhan ataupun setiap bagian dari ponton di bersihkan dari karat atau kerak yang menempel pada permukaan dengan bahan abrasive berkecepatan yang sangat tinggi untuk membuat profil untuk cat (Coating). Fungsi Blasting adalah untuk memudahkan cairan cat untuk bisa menempel pada permukaan benda kerja.

Sedangkan coating adalah proses pelapisan dalam bentuk cair,pasta atau bubuk yang apabila diaplikasikan diatas subtrat akan membentuk lapisan film tak tembus cahaya dengan sifat teknis proteksi, dekorasi atau spesifik. Manfaat pengecatan antara lain adaah mencegah korosi, kontrol Fouling (Fouling dapat meningkatkan hambatan $40 \%$ ), penampilan kosmetik, penyerapan sinar surya rendah,tahan panas,anti selip (menggunakan aluminium oxide).

O. Final Inspection

Final Inspection adalah suatu kegiatan akhir penilaian terhadap suatu produk, apakah produk itu baik atau rusak ataupun untuk penentuan apakah suatu lot dapat diterima atau tidak berdasarkan metode \& standard yang sudah ditentukan. Dengan kata lain inspeksi adalah kegiatan operasional untuk memeriksa material atau part yang diperlukan oleh proses produksi untuk dapat memenuhi spesifikasi pada proses berikutnya atau memenuhi spesifikasi pelanggan sebelum produk tersebut dikirim. Inpeksi mencakup pengukuran material, partpart atau produk jadi dengan methode tertentu dan membandingkan hasilnya dengan standard (drawing, JIS dsb) untuk penentuan keterterimaannya. Pengukuran yang dimaksudkan disini, tidak hanya bersifat dimensional (Vernier caliper, Micrometer, dsb) ataupun pengujian Properties (hardness serta komposisi kimia) tetapi juga Sensory (Noise check,Visual check : noda dan Crack).

\section{KESIMPULAN}

Proses Repairing ponton merupakan suatu proses perbaikan ponton floating dock agar kekuatan angkat floating dock tetap terjaga, proses tersebut memerlukan tahapan-tahapan yang sedetail mungkin mulai dari Handling, Ident Material, Marking, Cutting, Bending, Joint Plate, Fit-up scantling, Joint Pannel, Welding, Firing, NDT, Blasting \& Coating, Final Inspection dan pengujian yang berkala untuk meminimalisir kesalahankesalahan yang akan timbul dalam proses pengerjaanya.

\section{REFERENSI}

[1] Bintoro, G.A. 1999. Dasar-Dasar Pekerjaan Las. Jilid 1. Penerbit Kanisius.Yogyakarta.

[2] Biro Klasifikasi Indonesia. 2006. Rules for The Classification and Construction of Seagoing Steel Ships, Volume II, Rules for Hull. Jakarta : Biro Klasifikasi Indonesia.

[3] Moch. Sofi, dkk. 2008. Teknik Konstruksi Kapal Baja. Jakarta: Indra kusna djaya.

[4] Santosa, I.G.M. 1999. Diktat Kuliah Perencanaan Kapal.Surabaya: ITS, FTK, Jurusan Teknik Perkapalan.

[5] Salmon, Charles, G. 1990. Struktur Baja. Edisi ke-3. Jilid I. Penerbit Gramedia,Jakarta Senior Manager, Manager, dan Pembimbing Lapangan Divisi Mesin, Hull Construction, Quality Control, Engineering, Renwas, Sarfas, K3L, Pimpro, Limbung, dan Outfitting Tim Penyusun. 2014. Buku Panduan Praktek Industri/Praktek Kerja Lapangan. Surabaya: Universitas Negeri Surabaya, Unipress .

[6] Timings, R, L. 1992. Engineering Materials. Volume 2. Penerbit Logman Group UK limited Malaysia.

[7] Wiryosumarto, Harsono. 1996. Teknologi Pengelasan Logam. Cetakan ke-7.PT. Pradnya Paramitha, Jakarta. 
